Cite as: Grohmann, C.H., 2015. Effects of spatial resolution on slope and aspect derivation for regional-scale analysis. Computers \&G Geosciences. 77:111-117. DOI:10.1016/j.cageo.2015.02.003

\title{
Effects of spatial resolution on slope and aspect derivation for regional-scale analysis
}

\author{
Carlos H. Grohmann \\ Institute of Energy and Environment, University of São Paulo, São Paulo, 05508-010, Brazil
}

\begin{abstract}
This paper investigates differences between morphometric parameters (slope and aspect) derived from a resampled DEM and resampled morphometric data derived from a medium resolution DEM, with examples for three study areas in South America selected to represent flatlands, hilly terrain, and mountain ranges. Using a low resolution DEM for regional scale morphometric analysis is not an optimal choice, since attenuation of elevation will strongly affect the distribution of calculated parameters. Unless bounded by computational constraints, one should choose to derive basic morphometric parameters from higher resolution data, and resample it to a coarser resolution as needed.
\end{abstract}

Keywords: geomorphometry, digital elevation model, SRTM, resampling, morphometric parameters, GRASS-GIS

\section{Introduction}

The widespread availability of medium to high resolution Digital Elevation Models (DEMs) has grown exponentially in the last years. While ASTER GDEM (Reuter et al., 2009) and SRTM (Farr et al., 2007) provide a global or near-global coverage at medium spatial resolution (30 to 90 $\mathrm{m}$ ), the forthcoming TanDEM-X will deliver a global dataset with a resolution of $12 \mathrm{~m}$ (Krieger et al., 2009) and the Open Topography initiative (Krishnan et al., 2011) aims to centralize the distribution of high-resolution (usually less than $5 \mathrm{~m}$ ) elevation data derived from airborne or ground-based LiDAR.

In the case of a regional-scale analysis, when areas as large as entire continents can be studied (Cogley, 1985; Lehner et al., 2008), use of medium/high resolution data may impose computational constraints in processing time, available memory or even software capability to handle large amounts of data.

One common alternative is to use coarser resolution DEMs, such as SRTM30_PLUS (Becker et al., 2009) with spatial resolution of about 1 kilometre, to derive morphometric data. Another option would be to use medium/high resolution DEMs to derive morphometric parameters and then resample these parameters to a coarser resolution.

This paper intends to investigate the differences between morphometric parameters (slope and aspect) derived from a resampled DEM and resampled morphometric data derived from a medium

Email address: guano@usp.br (Carlos H. Grohmann)

URL: http://www.iee.usp.br (Carlos H. Grohmann) 
resolution DEM. Examples are presented for three study areas in South America (Fig. 1), one in the Amazon region (gentle, flat topography), one in Southeastern Brazil (Minas Gerais State mixed topography with hills and ranges) and one in the Andes Chain (mountainous relief).

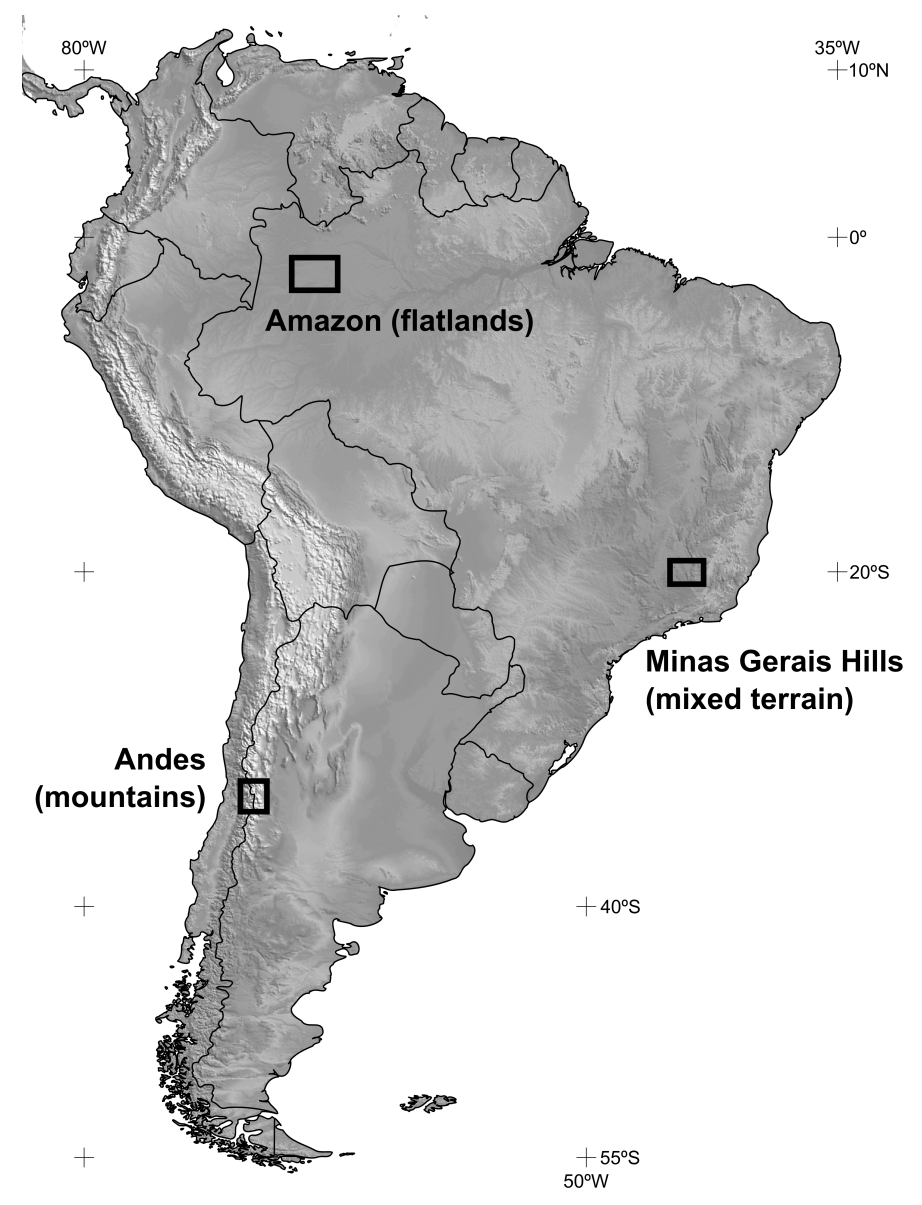

Figure 1. Location of study areas in South America.

\section{Previous works}

Several studies have been done on the effects of spatial scale on topographic modelling and its implications on derived parameters. A thorough revision on the subject can be found in Chow and Hodgson (2009) and Chen and Zhou (2013).

Evans (1980) was likely the first to report a decrease in mean and standard deviation of slope with an increase in grid size. Chang and Tsai (1991) showed that accuracy of slope and aspect decrease as a DEM resolution decreases (coarsens), and that the larger slope differences occur in areas of steep relief, while larger aspect differences are in low relief areas. Hodgson (1995) used a synthetic surface to examine the angular errors in slope and aspect calculated with different algorithm and concluded that morphometric parameters should be derived from higher resolution data whenever possible.

Gao (1997) studied the influence of spatial resolution at the micro-scale of three $1 \mathrm{~km}^{2}$ areas representing a valley, a peak and a ridge; he reports that resolution has little influence on mean gradient, but affects significantly the standard deviation of slope, especially for a simple terrain. Florinsky (1998) mapped the root mean square errors (RMSE) of the local topographic variables slope, aspect, plan and profile curvatures, in order to analyse their accuracy. He concluded that high data errors on these variables are typical for flat areas. 
In a study using synthetic surfaces, Zhou and Liu (2004) found that in a high-resolution DEM the influence of data error is stronger than algorithm errors, which will play an important role in low-resolution data. Kienzle (2004) used photogrammetrically derived elevation points to generate DEMs with grid sizes ranging from 5 to $100 \mathrm{~m}$ of four study areas with steep, moderately sloped and flat relief. His results showed that with the exception of elevation and local slope, all DEM derivatives (aspect, plan and profile curvature, wetness index) are not represented realistically when derived from a coarse DEM.

Dobos et al. (2005) recommended deriving morphometric data from a $90 \mathrm{~m}$ SRTM and then resampling it to $990 \mathrm{~m}$ resolution for delineating SOTER (World SOil and TERrain Digital Database) Terrain Units. Korup et al. (2007) studied the relation between giant landslides and topography using SRTM30 as a base DEM. A measure of local relief (maximum elevation minimum elevation) was used instead of local slope due the substantial underestimation of slope by SRTM30 data.

Li et al. (2011) analysed how LiDAR DEM errors in a hummocky landscape are related to the identification of real depressions, and suggest smoothing of raw LiDAR data instead of coarsening, to produce a more realistic surface while maintaining the topographic characteristics of the landscape.

As an alternative approach to change the scale of topographic data Zhou and Chen (2011) proposed a method to construct a drainage-constrained TIN (triangulated irregular network), which yelded better results in computing terrain parameters at coarser resolutions than the resampling method. Chen and Zhou (2013) proposed using a scale-adaptive digital elevation model (S-DEM) based on a compound point extraction (CPE) algorithm that extracts surface 'significant points' from a high-resolution DEM according to their degree of importance (DOI) to the scale of an application.

Shih (2014) investigated the differences in information content between different resolutions (1-arcsec, 3-arcsec, 30-arcsec) of SRTM data over three areas in the United States selected to represent flat area, moderate terrain, and mountain ranges. He concluded that if the 30-arcsec DEM was derived directly from the 1-arcsec data, its height accuracy would be improved by approximately $10 \%$.

\section{Methods}

\subsection{DEM preparation and processing}

SRTM V4 elevation data was downloaded from CIAT-CSI website (Jarvis et al., 2008) and processed in GRASS-GIS version 6.4.5 (Neteler et al., 2012; GRASS Development Team, 2014). After merging the data tiles for each area, a bilinear interpolation (Brovelli and Cannata, 2004) was performed at the original resolution of 3 arcsec to avoid artifacts in derived parameters (Carter, 1992), and slope and aspect were calculated using Horn's formula (Horn, 1981).

Resampling of elevation and slope data was done with GRASS' r.resamp.stats command, which resamples raster map layers by aggregating the values of all input cell whose centres lie within the output cell or which intersect the output cell (in this case, input cell values will be weighted according to the proportion of the source cell which lies inside the output cell) (GRASS Development Team, 2014).

In order to streamline the process and ensure reproducibility (Barnes, 2010), all steps were run through Python scripts (Python Software Foundation, 2013) using the Pygrass library (Zambelli et al., 2013) to access GRASS datasets. The scripts are available upon request to the author.

\subsection{Parameters derived from a resampled DEM}

For each study area, the base DEM was resampled (averaged) at resolutions of $0^{\circ} 0$ '10" (approx. $0.3 \mathrm{~km}$ at the Equator), 0 0'15" $(\sim 0.45 \mathrm{~km}), 0^{\circ} 0^{\prime} 20^{\prime \prime}(\sim 0.6 \mathrm{~km}), 0^{\circ} 0{ }^{\prime} 25^{\prime \prime}(\sim 0.75 \mathrm{~km}), 0^{\circ} 0^{\prime} 30^{\prime \prime}$ $(\sim 0.9 \mathrm{~km}), 0^{\circ} 0^{\prime} 35^{\prime \prime}(\sim 1.05 \mathrm{~km}), 0^{\circ} 0^{\prime} 40^{\prime \prime}(\sim 1.2 \mathrm{~km}), 0^{\circ} 0^{\prime} 45^{\prime \prime}(\sim 1.4 \mathrm{~km}), 0^{\circ} 0^{\prime} 50^{\prime \prime}(\sim 1.55 \mathrm{~km})$, $0^{\circ} 05^{\prime}=(\sim 1.7 \mathrm{~km})$ and $0^{\circ} 01^{\prime}(\sim 1.85 \mathrm{~km})$. Slope and aspect were calculated and aspect values were converted from Cartesian to azimuth angles as (Grohmann, 2004): 


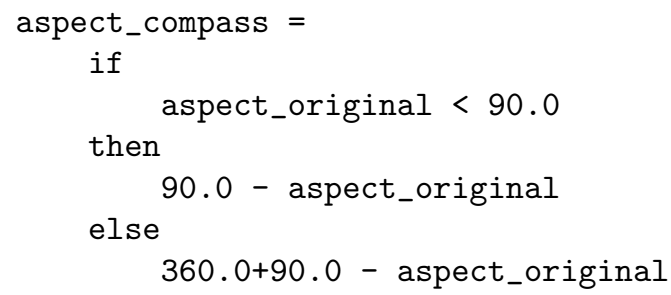

\subsection{Resampled parameters from a base DEM}

In this case, original values of slope and aspect (calculated at $0^{\circ} 0{ }^{\prime} 03^{\prime \prime}$ resolution) were re-

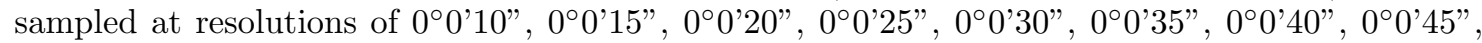
$0^{\circ} 0^{\prime} 50^{\prime \prime}, 0^{\circ} 0^{\prime} 55^{\prime}$ and $0^{\circ} 01^{\prime}$. Slope was taken as the average of values and aspect as a vector mean.

To evaluate the vector mean of aspect, raster algebra ( $r$.mapcalc command, Shapiro and Westervelt 1991) was used to calculate $\mathrm{x}$ and $\mathrm{y}$ direction cosines as:

$$
\begin{aligned}
& \text { Cosine } X=\sin (\text { aspect }) \\
& \text { Cosine } Y=\cos (\text { aspect })
\end{aligned}
$$

The sum of direction cosines was obtained with the r.resamp.stats command, and the final vector mean was calculated with raster algebra as:

$$
\text { aspectVector }=\operatorname{atan}\left(\sum \operatorname{Cosine} Y, \sum \operatorname{Cosine} X\right)
$$

The differences between both methods of obtaining aspect and slope values in a coarser resolution was done by comparing: a) density plots (Cox, 2007) of all calculated maps (Fig. 2, 3) and b) plots of the correlation between the original parameter $\left(0^{\circ} 0\right.$ '03" resolution $)$ and resampled values (Fig. 4).

Statistical analyses of slope were performed with the Python libraries Scipy, Numpy and Matplotlib (Oliphant, 2006; Hunter, 2007; The SciPy community, 2013). Density plots were calculated using Scott's Rule to determine optimal bandwidth (Silverman, 1986; Scott, 1992).

To analyse aspect, a circular variable (Fisher, 1993), the statistical language R (R Core Team, 2013) was used. The circular package (Agostinelli and Lund, 2013) implements Taylor's ruleof-thumb for selecting the optimal bandwidth of a von Mises kernel density estimator (Taylor, 2008).

Correlations between resampled and original values were performed on a set of 10,000 random samples for the Andes and Minas Gerais areas and 20,000 samples for the Amazon area. Correlations for aspect were computed with a circular version of the Pearsons product moment correlation (Jammalamadaka and SenGupta, 2001).

\section{Results}

Resampling the DEM prior to calculating derivatives will attenuate relief and slope will systematically reduce as the resolution becomes coarser (Carter, 1992; Zhang and Montgomery, 1994; Chow and Hodgson, 2009). In the Amazon flatlands (Fig. 2A), maximum slope is reduced from $19.6^{\circ}$ in the original DEM to $8.7^{\circ}$ with a resolution of $0^{\circ} 0 ' 10^{\prime \prime}$ and to only $0.7^{\circ}$ at $0^{\circ} 01^{\prime}$. Values of mean, median, standard deviation, skewness and kurtosis decrease, although skewness and kurtosis remain positive.

In the Hills of Minas Gerais (Fig. 2C), maximum slope decreases from $67.2^{\circ}$ at the original resolution of $0^{\circ} 0 ' 03^{\prime \prime}$ to $44.9^{\circ}$ at $0^{\circ} 0^{\prime} 10^{\prime \prime}$ and to $15.6^{\circ}$ at $0^{\circ} 01^{\prime}$. In the Andes Mountains (Fig. 2E), an originally bimodal distribution is becomes unimodal as resolution decreases. Maximum slope is reduced from $76.3^{\circ}$ at $0^{\circ} 00^{\prime} 03^{\prime \prime}$ to $59.2^{\circ}$ at $0^{\circ} 0^{\prime} 10^{\prime \prime}$ and to $29.7^{\circ}$ at $0^{\circ} 01^{\prime}$. In both areas, mean and standard deviation are reduced, while skewness and kurtosis increase. 
Resampled slope values change less about the original. In the Amazon (Fig. 2B) and in Minas Gerais (Fig. 2D), mean and median values remain about the same, while standard deviation, skewness and kurtosis decrease. Maximum slope is reduced from $19.6^{\circ}$ at $0^{\circ} 0^{\prime} 03^{\prime \prime}$ to $14.2^{\circ}$ at $0^{\circ} 0^{\prime} 10^{\prime \prime}$ and to $5.7^{\circ}$ at $0^{\circ} 01^{\prime}$ in the Amazon. In Minas Gerais, slope decreases from $67.2^{\circ}$ at $0^{\circ} 0$ '03" to $58.6^{\circ}$ at $0^{\circ} 0^{\prime} 10^{\prime \prime}$ and to $30.5^{\circ}$ at $0^{\circ} 01^{\prime}$ '.

The bimodal character of slopes in the Andes Mountains is preserved (Fig. 2F), with a decrease in standard deviation. Maximum slope is reduced from $76.3^{\circ}$ at $0^{\circ} 0$ '03" to $68.1^{\circ}$ at $0^{\circ} 0$ ' $10^{\prime \prime}$ and to $47.2^{\circ}$ at $0^{\circ} 01^{\prime}$.
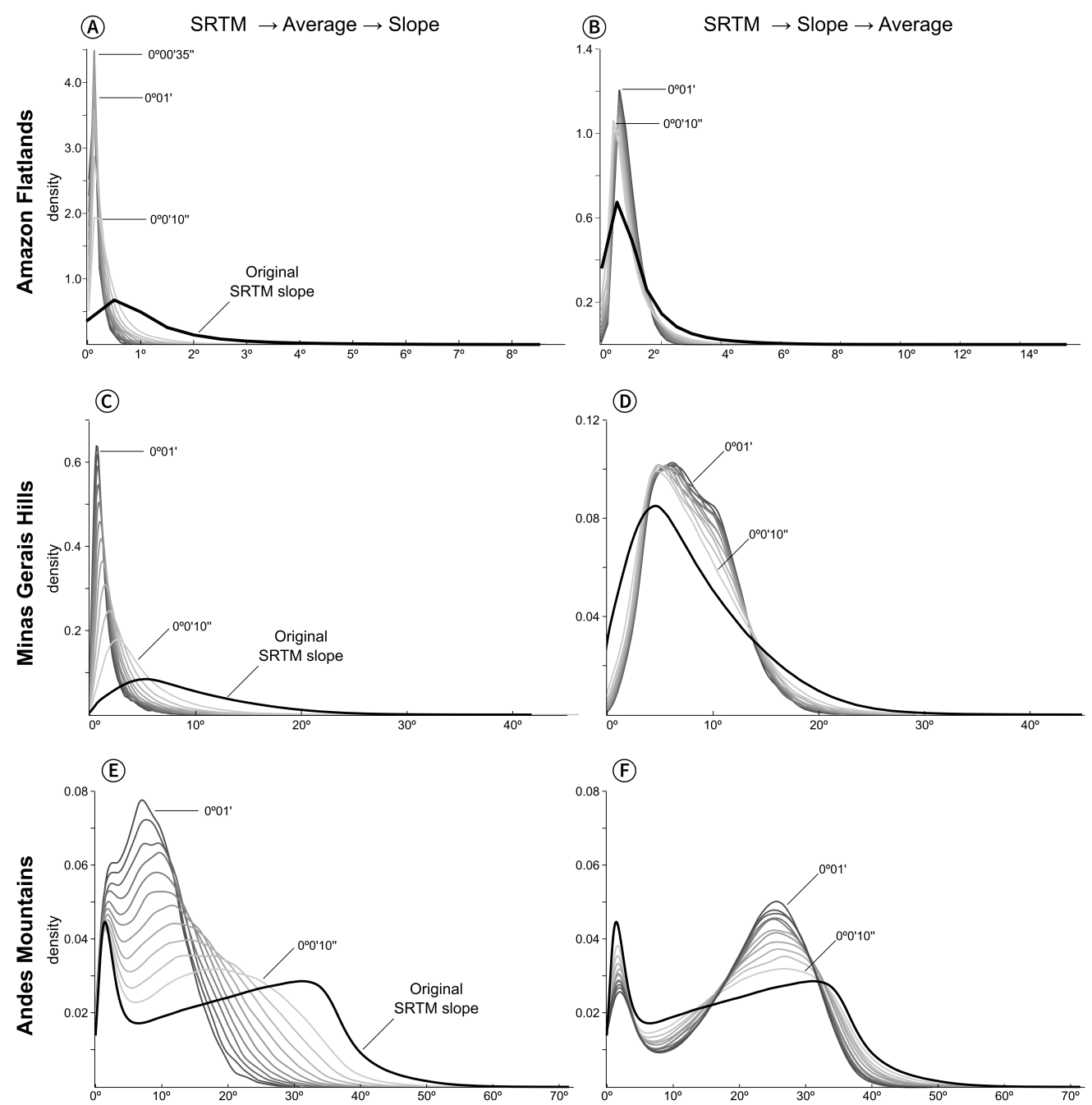

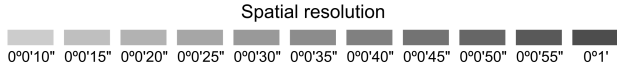

Figure 2. Density plots for slope derived from a resampled DEM (A,C,E) and resampled slope derived from a base DEM $(\mathrm{B}, \mathrm{D}, \mathrm{F})$.

Density plots of aspect (Fig. 3) show that peaks and valleys in the density curve are intensified as resolution decreases, for both methods studied here. In the Amazon flatlands, when resampling the DEM before calculating aspect, the deepening of the valley at WSW is accompanied by the intensification of a 'shoulder' at N and SE. Resampled aspects result in a curve with a deep valley at WSW and a wide peak centred on E.

In the Minas Gerais Hills, density curves of aspect calculated from an averaged DEM (Fig. 
3C) are more similar to the original one than those of averaged aspect values (Fig. 3D), which present a wide peak at $\mathrm{N}$ and a deep valley at S. Aspect of the Andes Mountains calculated from a resampled DEM (Fig. 3E) shows a stronger intensification of the peak at $\mathrm{W}$ than averaged aspect values (Fig. 3F).
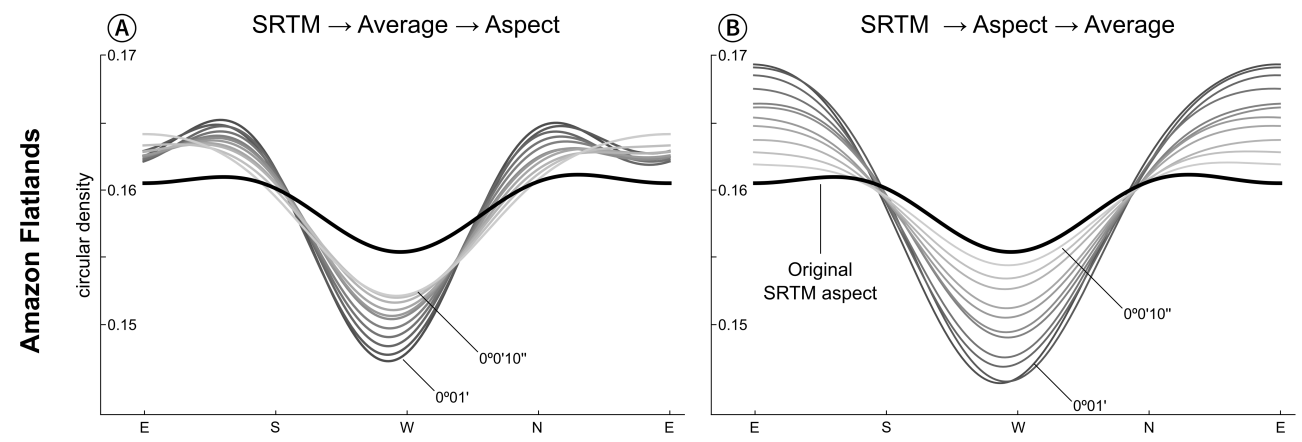

(c)
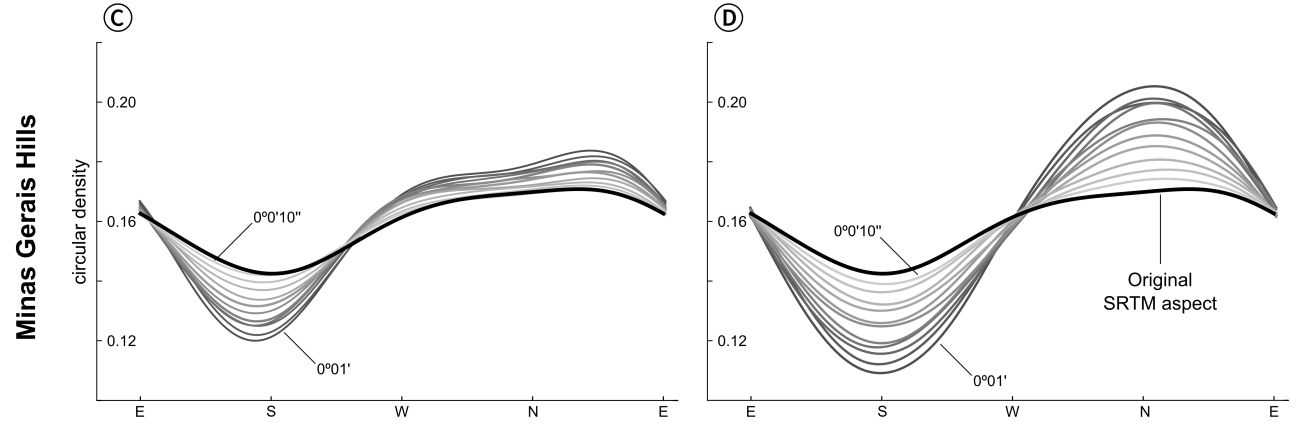

(E)

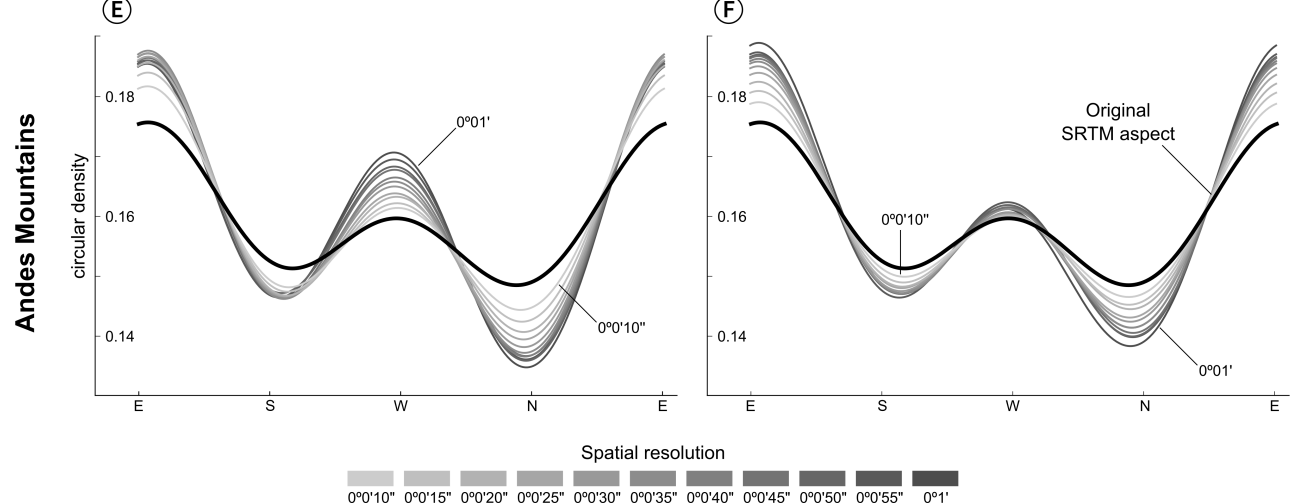

Figure 3. Density plots for aspect derived from a resampled DEM (A,C,E) and resampled slope derived from a base DEM (B,D,F).

Correlation plots between the calculated parameters and the original values are presented in figure 4. Solid lines represent aspect, with values of a circular version of the Pearsons product moment correlation. Dashed lines represent slope, with values of R-square. Grey colour indicates parameters calculated from an averaged DEM, while black colour is used for averaged parameters. In all plots, averaged parameters have a higher correlation with the original values than those calculated from an averaged DEM. In general, correlation decreases with spatial resolution, but for the same resolution, correlations tend to be higher for high-relief areas (i.e, Andes Mountains $>$ Minas Gerais Hills > Amazon Flatlands). 
(A) Amazon Flatlands
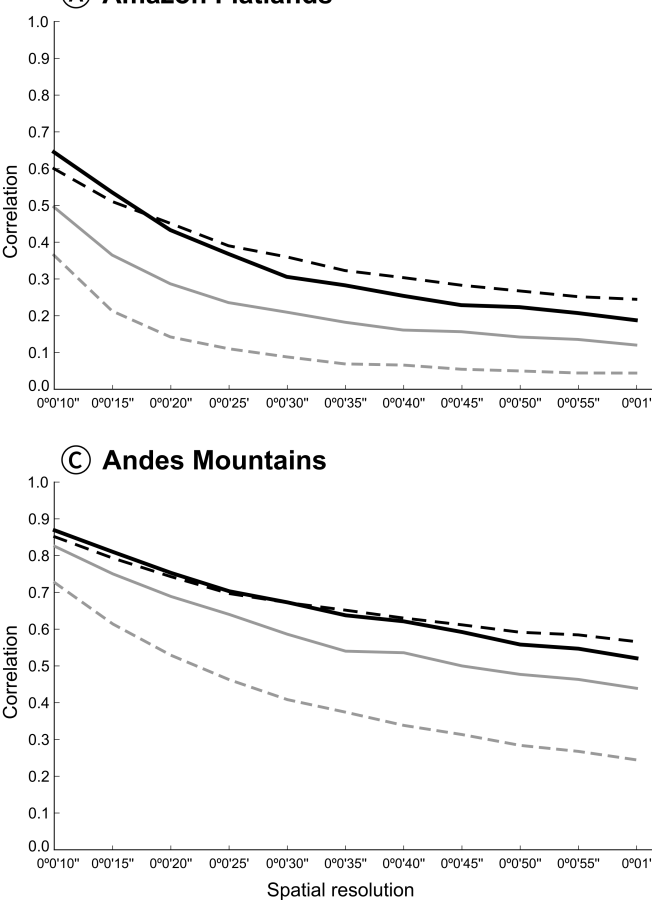

(B) Minas Gerais Hills

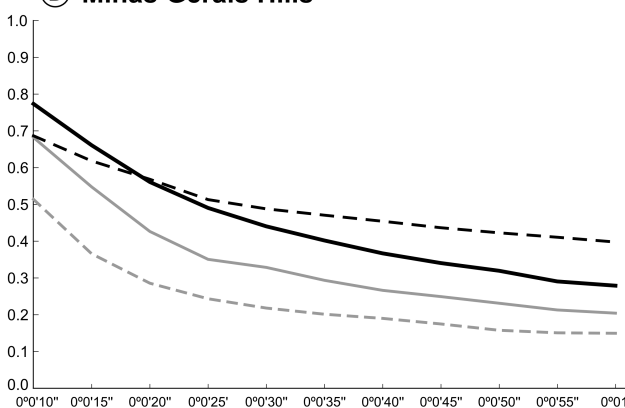

Figure 4. Plots of correlation between the original morphometric parameter (00'03" resolution) and resampled values.

\section{Concluding remarks}

The data presented in this paper suggests that using a low resolution DEM (i.e., created by averaging higher-resolution data) for regional scale morphometric analysis is not an optimal choice, since attenuation of elevation will strongly affect the distribution of calculated parameters. Slope is more prone to changes as resolution is coarsened, with a strong decrease in maximum values, decrease in mean values and standard deviation. In the mountainous area of the Andes, an originally bimodal distribution of slope became unimodal at coarser resolutions.

Resampled slope values are more correlated to the original ones, with less decrease in maximum values, and maintaining similar mean values. The bimodal characteristic of slopes in the Andes area is preserved. Aspect changes less with resampling (for both methods), but peaks and valleys in the density curve are intensified as resolution decreases.

The observations in this study cannot be considered completely new, but it is hoped that the results presented here can benefit other researcher in this field.

Unless bounded by computational constraints, one should choose to derive basic morphometric parameters from higher resolution data, and resample it to a coarser resolution as needed.

\section{Acknowledgements}

This study was supported by CNPq (306294/2012-5) and FAPESP (2009/17675-5) research grants to CHG and is co-funded by FAPESP (BIOTA 2012/50260-6, 2013/50297-0), NSF (DEB 1343578), and NASA. I want to thank John Gallant and Scott Peckham for the fruitful discussions on the subject and the anonymous reviewers for their criticism and suggestions, which helped to improve this paper. 


\section{References}

Agostinelli, C., Lund, U., 2013. R package circular: Circular Statistics (version 0.4-7). CA: Department of Environmental Sciences, Informatics and Statistics, Ca' Foscari University, Venice, Italy. UL: Department of Statistics, California Polytechnic State University, San Luis Obispo, California, USA.

Barnes, N., 2010. Publish your computer code: it is good enough. Nature 467, 753.

Becker, J.J., Sandwell, D.T., Smith, W.H.F., Braud, J., Binder, B., Depner, J., Fabre, D., Factor, J., Ingalls, S., Kim, S.H., Ladner, R., Marks, K., Nelson, S., Pharaoh, A., Trimmer, R., Von Rosenberg, J., Wallace, G., Weatherall, P., 2009. Global Bathymetry and Elevation Data at 30 Arc Seconds Resolution: SRTM30_PLUS. Marine Geodesy 32, 355-371. http://ww.tandfonline.com/doi/pdf/10.1080/01490410903297766.

Brovelli, M.A., Cannata, M., 2004. Digital terrain model reconstruction in urban areas from airborne laser scanning data: the method and an example for Pavia (northern Italy). Computers \& Geosciences 30, 325-331.

Carter, J.R., 1992. The Effect Of Data Precision On The Calculation Of Slope And Aspect Using Gridded Dems. Cartographica: The International Journal for Geographic Information and Geovisualization 29, 22-34.

Chang, K., Tsai, B., 1991. The effect of DEM resolution on slope and aspect mapping. Cartography and Geographic Information Systems 18, 69-77. http://www.tandfonline.com/doi/pdf/10.1559/152304091783805626.

Chen, Y., Zhou, Q., 2013. A scale-adaptive DEM for multi-scale terrain analysis. International Journal of Geographical Information Science 27, 1329-1348. http://www.tandfonline.com/doi/pdf/10.1080/13658816.2012.739690.

Chow, T.E., Hodgson, M.E., 2009. Effects of lidar post-spacing and DEM resolution to mean slope estimation. International Journal of Geographic Information Science 23, 1277-1295.

Cogley, J.G., 1985. Hypsometry of the continents. Zeitschrift für Geomorphologie Suppl.-Bd. 53, 48.

Cox, N.J., 2007. Kernel estimation as a basic tool for geomorphological data analysis. Earth Surface Processes and Landforms 32, 1902-1912.

Dobos, E., Daroussin, J., Montanarella, L., 2005. An SRTM-based procedure to delineate SOTER terrain units on 1:1 and 1:5 million scales. volume EUR 21571 EN. Office for Official publications of the European Communities, Luxembourg.

Evans, I.S., 1980. An integrated system of terrain analysis and slope mapping. Zeitschrift für Geomorphologie Suppl.-Bd. 36, 274-295.

Farr, T.G., Rosen, P.A., Caro, E., Crippen, R., Duren, R., Hensley, S., Kobrick, M., Paller, M., Rodriguez, E., Roth, L., Seal, D., Shaffer, S., Shimada, J., Umland, J., Werner, M., Oskin, M., Burbank, D., Alsdorf, D., 2007. The Shuttle Radar Topography Mission. Review of Geophysics 45, RG2004.

Fisher, N.I., 1993. Statistical Analysis of Circular Data. Cambridge Univ. Press, Cambridge.

Florinsky, I.V., 1998. Accuracy of local topographic variables derived from digital elevation models. International Journal of Geographical Information Science 12, 47-61.

Gao, J., 1997. Resolution and accuracy of terrain representation by grid DEMs at a micro-scale. International Journal of Geographical Information Science 11, 199-212. http://www.tandfonline.com/doi/pdf/10.1080/ 136588197242464.

GRASS Development Team, 2014. Geographic Resources Analysis Support System (GRASS GIS) Software, Version 6.4.5. Http://grass.osgeo.org, [accessed 20 January 2015].

Grohmann, C.H., 2004. Morphometric analysis in Geographic Information Systems: applications of free software GRASS and R. Computers \& Geosciences 30, 1055-1067.

Hodgson, M.E., 1995. What cell size does the computed slope/aspect angle represent? Photogrammetric Engineering and Remote Sensing 61, 513-517.

Horn, B.K.P., 1981. Hill Shading and the Reflectance Map. Proceedings of the IEEE 69, 14-47.

Hunter, J.D., 2007. Matplotlib: A 2D graphics environment. Computing In Science \& Engineering 9, 90-95. Available at http://matplotlib.sourceforge.net/, last access 06/06/2011.

Jammalamadaka, S.R., SenGupta, A., 2001. Topics in Circular Statistics. World Scientific Press, Singapore.

Jarvis, A., Reuter, H.I., Nelson, A., Guevara, E., 2008. Hole-filled SRTM for the globe Version 4, available from the CGIAR-CSI SRTM 90m Database (http://srtm.csi.cgiar.org). Last accessed: 11 March, 2013.

Kienzle, S., 2004. The effect of DEM raster resolution on first order, second order and compound terrain derivatives. Transactions in GIS 8, 83-111.

Korup, O., Clague, J.J., Hermanns, R.L., Hewitt, K., Strom, A.L., Weidinger, J.T., 2007. Giant landslides, topography, and erosion . Earth and Planetary Science Letters 261, $578-589$.

Krieger, G., Zink, M., Fiedler, H., Hajnsek, I., Younis, M., Huber, S., Bachmann, M., Gonzalez, J., Schulze, D., Boer, J., Werner, M., Moreira, A., 2009. The TanDEM-X Mission: Overview and status, in: Radar Conference, 2009 IEEE, pp. 1-5.

Krishnan, S., Crosby, C., Nandigam, V., Phan, M., Cowart, C., Baru, C., Arrowsmith, R., 2011. OpenTopography: a services oriented architecture for community access to LIDAR topography, in: Proceedings of the 2nd International Conference on Computing for Geospatial Research \& Applications, ACM, New York, NY, USA. pp. $7: 1-7: 8$.

Lehner, B., Verdin, K., Jarvis, A., 2008. New Global Hydrography Derived From Spaceborne Elevation Data. Eos, Transactions American Geophysical Union 89, 93-94.

Li, S., MacMillan, R., Lobb, D.A., McConkey, B.G., Moulin, A., Fraser, W.R., 2011. Lidar $\{$ DEM $\}$ error analyses and topographic depression identification in a hummocky landscape in the prairie region of Canada . Geomorphology $129,263-275$.

Neteler, M., Bowman, M.H., Landa, M., Metz, M., 2012. GRASS GIS: A multi-purpose open source GIS. Environmental Modelling \& Software 31, 124-130.

Oliphant, T., 2006. Guide to NumPy. Trelgol Publishing. 
Python Software Foundation, 2013. Python Programming Language, version 2.7. Available at http:// www.python.org/, last access 15/Aug/2013.

R Core Team, 2013. R: A Language and Environment for Statistical Computing. R Foundation for Statistical Computing. Vienna, Austria.

Reuter, H.I., Hengl, T., Gessler, P., Soille, P., 2009. Chapter 4 Preparation of DEMs for Geomorphometric Analysis, in: Hengl, T., Reuter, H.I. (Eds.), Geomorphometry: Concepts, Software, Applications. Elsevier, Amsterdam. volume 33 of Developments in Soil Science, pp. 87-120.

Scott, D.W., 1992. Multivariate Density Estimation: Theory, Practice, and Visualization. John Wiley \& Sons, New York.

Shapiro, M., Westervelt, J., 1991. r.mapcalc: An Algebra for GIS and Image Processing. Technical Report. U.S. Army Construction Engineering Research Laboratory.

Shih, P., 2014. Evaluating the Information Loss of SRTM DEM Data with Different Grid Sizes. Journal of Surveying Engineering 140, 04014010.

Silverman, B.W., 1986. Density Estimation for Statistics and Data Analysis. Chapman \& Hall CRC Monographs on Statistics \& Applied Probability, Taylor \& Francis.

Taylor, C.C., 2008. Automatic bandwidth selection for circular density estimation. Computational Statistics and Data Analysis 53, 3493?3500.

The SciPy community, 2013. SciPy Reference Guide - Release 0.13.0.

Zambelli, P., Gebbert, S., Ciolli, M., 2013. Pygrass: An Object Oriented Python Application Programming Interface (API) for Geographic Resources Analysis Support System (GRASS) Geographic Information System (GIS). ISPRS International Journal of Geo-Information 2, 201-219.

Zhang, W., Montgomery, D., 1994. Digital elevation model grid size, landscape representation, and hydrologic simulations. Water Resources Research 30, 1019-1028.

Zhou, Q., Chen, Y., 2011. Generalization of DEM for terrain analysis using a compound method. \{ISPRS\} Journal of Photogrammetry and Remote Sensing 66, 38-45.

Zhou, Q., Liu, X., 2004. Error analysis in grid-based slope and aspect algorithms. Photogrammetric Engineering and Remote Sensing 70, 957-962. 